\title{
Pertencimento negro e reflexões acerca do feminino na literatura de Cristiane Sobral
}

\section{Black belonging and reflections about the feminine in Cristiane Sobral's literature}

Entrevista concedida à Denise Lima 
Cristiane Sobral - Mestre em Arte e Bacharel em Interpretação pela Universidade de Brasília. Licenciada em Educação Artística (UCB). Especialista em Docência Superior, (UGF), RJ. Últimos espetáculos de teatro: Não vou mais lavar os pratos e Recordar é Preciso. Último filme: O Tiro, de João Inácio. Coordenadora de Modernização na Fundação Cultural Palmares/MinC. Diretora de Gestão e Produção Cultural no Sindicato dos Escritores do DF. Escritora imortal ocupante da cadeira 34 na Academia de Letras do Brasil. Iniciou suas publicações na antologia Cadernos Negros em 2000 e desde então tem publicado em vários volumes da série. Tem atuado como parecerista em editais do Ministério da cultura com ênfase na cultura negra. Escreve no blog: www.cristianesobral.blogspot.com

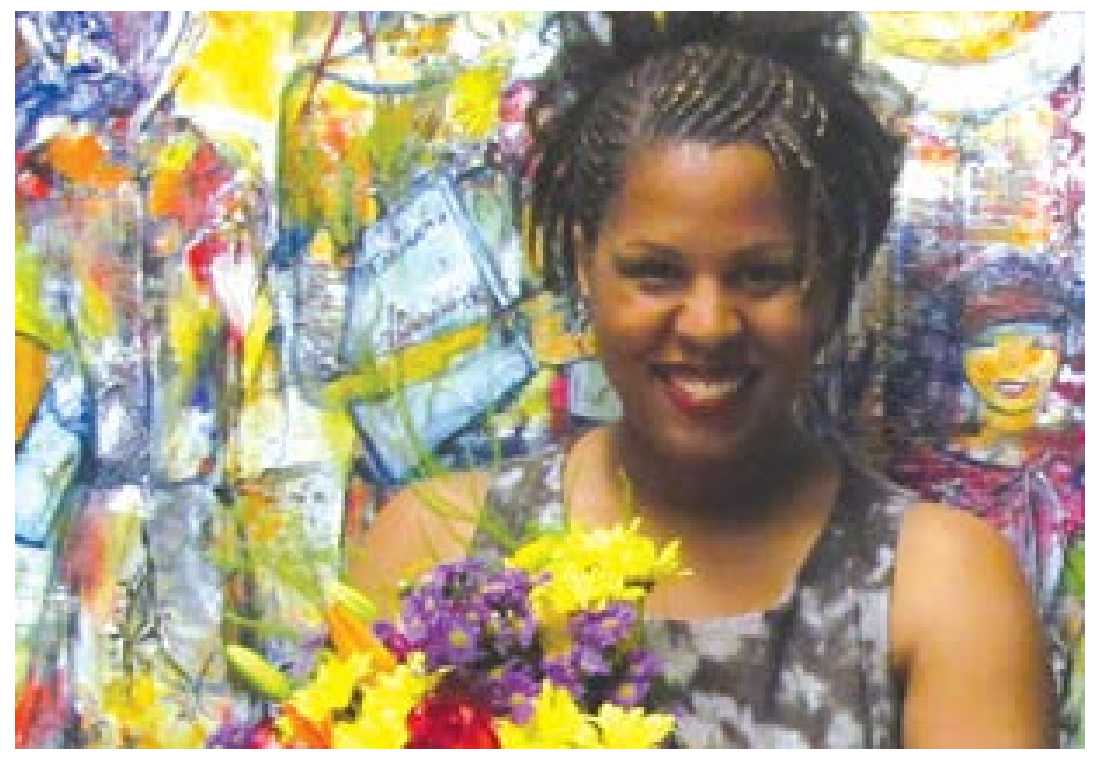

Entrevista com Cristiane Sobral em 18 de novembro de 2014 Foto: Diogo Hamlet

ISSN: 1414.5731

E-ISSN: 2358.6958

\footnotetext{
${ }^{1}$ Doutoranda em Educação na Universidade Católica de Brasília (UCB). Bolsista CAPES. Voluntária da Organização das Nações Unidas para a Educação (UNESCO). Professora da Secretaria de Educação do Distrito Federal (SEDF). 
A entrevista com a escritora, atriz e professora de teatro Cristiane Sobral, carioca, residente em Brasília desde 1990, compõe minha tese de doutorado em andamento, que estuda as relações raciais contemporâneas em relação ao corpo e aos cabelos das jovens negras na escola. Neste depoimento, Cristiane Sobral fala sobre a presença marcante da temática negra e feminina em sua obra e quais os desdobramentos desta escolha em sua escrita literária.

\section{Denise Lima - Em sua obra, há várias referências à questão da aparência? O que a levou a escrever sobre o tema? Quando tudo co- meçou?}

Cristiane Sobral - Tudo começou na infância, período em que sofri muita discriminação de gênero e raça no bairro e na escola. A escola foi uma grande antagonista. Até hoje percebo que a escola, da forma como está configurada, a formação dos professores, o ensino, não está adequado para oferecer, com raras exceções, uma educação étnico-racial que atenda a questão das diferenças no ambiente estudantil.

Desde criança, questiono o não-lugar dos cabelos crespos e dos corpos negros, os estereótipos atribuídos aos afro-brasileiros, pra falar especificamente do gênero feminino, as meninas negras ocupam quando muito, um padrão anti-barbie, onde são taxadas de "feias", de ter o cabelo "ruim". Na minha infância, não haviam bonecas negras, desenhos animados com personagens negras, os contos de fadas não tinham personagens negras, princesas ou protagonistas. A Xuxa tinha paquitas loiras. E estava na TV todos os dias com aquele padrão único e impossível.

O eurocentrismo predominante no país com a maior população negra fora da África é uma das minhas reflexões constantes. Nos dias de hoje, quase todas as mulheres brasileiras estão empenhadas em ter um cabelo nos padrões, atendendo o mercado, não é à toa que o Brasil ocupa, segundo pesquisas recentes, o primeiro lugar no mundo em consumo de cosméticos.

Mas estamos avançando. Há um movimento de resistência, os encontros de meninas que estão criando uma contra cultura, como o "Encrespa Geral", nas redes sociais também encontramos várias páginas e grupos com alternativas à estética lisa, enfim, outros espaços estão surgindo. Desde o surgimento do movimento negro no Brasil, da independência dos países africanos, a influência estadunidense, enfim, muita informação, imagens foram projetadas no subconsciente e estão germinando.

A adoção do programa de ações afirmativas nas universidades também contribui para essa transformação em todos os setores da sociedade, assim como o advento da Lei 10.639/03 que institui a obrigatoriedade do ensino de África e dos negros nas escolas, embora a lei ainda não esteja totalmente implantada nos estabelecimentos de ensino.

Denise Lima - Qual o motivo para eleger personagens negros em suas obras? E as mulheres negras, seus corpos e cabelos? Ao clamar: "Abaixo a chapinha no cabelo da neguinha", qual é sua intenção? É delicado problematizar este assunto? 
Cristiane Sobral - Estou empenhada em provocar a reflexão sobre a humanidade de negros e negros além dos estigmas, escrevo sobre sua subjetividade em minhas obras, quero contar nossas histórias, nossas memórias, destacar nosso legado na construção planetária. Temos muita história para contar, a história negra é uma história de resistência, de beleza, remete a outros pontos de vista, sai da berlinda do opressor, há outros contornos de realidade em nossas memórias, muitos silêncios que ficaram no vácuo.

As mulheres negras não tiveram muitas oportunidades, não tiveram, nos calabouços da história, voz, vez e lugar. Seus corpos estiveram a serviço, não puderam protagonizar e mesmo quando o fizeram, suas conquistas não foram divulgadas. Quem já ouviu falar em Maria Firmina dos Reis? Em Carolina Maria de Jesus? Em Conceição Evaristo? São nomes de escritoras negras de expressão ainda desconhecidas do grande público. Temos que levar esse legado adiante, muito além dos estereótipos.

"Abaixo a chapinha no cabelo da neguinha" não é nenhuma ditadura do cabelo crespo, isso seria um atraso, quero sim, provocar a reflexão, a perspectiva do conhecimento e da descoberta do próprio cabelo, da sua textura, da reinvenção desses conceitos de "cabelo ruim", do direito de fazer as próprias escolhas.

É possível desafiar a indústria de cosméticos e o capitalismo aprendendo inclusive a cuidar dos cabelos em casa, porque não? Existe toda uma discussão sobre os prejuízos da química dos alisantes, claro que as empresas fabricantes não estão interessadas em divulgar isso, mas porque não podemos discutir isso? Cabelo também é política. É forma de empoderamento, identidade, aceitação. A gente só pode ser o que a gente é. Cabelo não é só um pelo. Pode ser um caminho de descoberta de outros penteados, de outros caminhos, outros modos de vida. É delicado discutir esse assunto, mas o problema é nosso, não dá para continuar empurrando pra debaixo do tapete.

Denise Lima - Sua última obra "Não vou mais lavar pratos" (SobraL, 2011a) denuncia o fenômeno da discriminação que atua sobre o tripé: gênero, raça e classe. $O$ que isso representa para a juventude negra feminina? Para muitos, não há um discurso hierárquico, que discrimina e reduz, em nossa sociedade, qual sua opinião?

Cristiane Sobral - Depois desse livro escrevi "Espelhos, miradouros, dialéticas da percepção" (Sobral, 2011a) e "Só por hoje vou deixar o meu cabelo em paz" (Sobral, 2014). Não vou mais lavar os pratos é uma obra muito tocante, sensível, atinge a todos, negros e brancos, está indo para a terceira edição, levou quase dez anos para ser produzida, na época em que comecei a escrever eu era adolescente, acreditava mesmo na poesia como um bálsamo, um respiro, um sopro de vida.

Essa obra representa muito! Recebo muito retorno de leitores de todos os cantos do país e também do exterior, países como Colômbia, Equador, Angola, África do Sul, Califórnia, Novo México, lugares onde levei essas letras e percebi o diálogo com os leitores, percebi que de fato a troca de sensações acontece é um resultado gratificante para o escritor. De fato a humanização ocorre sim, ouço muitos relatos, quem 
é negro sente na pele, quem é branco sente também, todo brasileiro e estrangeiro pode refletir sobre o machismo, o racismo, o preconceito e toda forma de opressão, todos podemos acreditar em uma transformação. Não é uma utopia para mudar o mundo, é o empreendedorismo de querer mudar, cada um muda o seu mundo e o mundo muda. "Não vou mais lavar os pratos" propõe uma mudança no estado de coisas. Um ponto de virada.

\section{Denise Lima - É possível uma identidade racial negra e feminina?}

Cristiane Sobral - Sim, abordo a especificidade da escrita negra considerando o ponto de vista da mulher, sua subjetividade, suas experiências, seus silêncios. Há muito a dizer nessa seara.

\section{Denise Lima - Tem algum projeto a caminho que possa revelar? 0 que busca como escritora?}

Cristiane Sobral - Projetos a caminho: Terceira edição do “Não vou mais lavar os pratos" em português, primeira edição em espanhol. Primeiro romance a caminho.

Busco aperfeiçoar cada dia mais a estética da sensibilidade. Como escritora, quero escrever e reescrever. Tenho obsessão pelas histórias, estórias, pelas memórias da resistência negra, seus paradoxos as contradições de um país tão diverso como o Brasil, os não ditos da diáspora negra, as dispersões humanas pelo planeta, a construção e desconstrução da identidade negra, a resignificação da identidade, a identidade múltipla.

\section{Denise Lima - Percebe como sua obra impacta seus leitores?}

Cristiane Sobral - Sempre me surpreendo positivamente. Percebo a identificação da obra com o leitor, o encontro com as palavras, o fortalecimento da autoestima provocado pelo texto, o empoderamento da palavra dita em muitos saraus e eventos pelo país onde meus textos têm sido apresentados, nas redes sociais os escritos também são muito divulgados pelos leitores. Meu ponto de vista é afirmativo. Sempre procuro exaltar a negritude, seus feitos, valorizar as contribuições femininas. Também me encantam o amor, a maternidade, a infância, a natureza, a religiosidade e a sensualidade.

\section{Denise Lima - Como tem sido a experiência de publicar em parce- ria com outros autores negros?}

Cristiane Sobral - Publicar com outros autores negros tem sido uma grande escola, uma alegria. Escrevo nos Cadernos Negros desde 2000, em várias edições algumas em prosa, outras em poesia, publiquei ao lado de muitos autores que admiro, tanto no caso dos autores mais antigos, como no caso dos mais novos. Há toda uma dinâmica de escolha de textos e temas que me inspira, assim como reflexões sobre a militância negra e vivências nos lançamentos das antologias e outros encontros. 
Ao publicar em parceria mostramos a força da literatura negra no escopo nacional e fortalecemos o nosso trabalho individual oportunizando a discussão sobre estratégias de publicação, o mercado editorial, distribuição dos exemplares, atendimento ao público leitor, só para citar algumas das questões importantes.

\author{
Não vou mais lavar os pratos \\ "Não vou mais lavar os pratos \\ Não vou mais lavar os pratos \\ Nem vou limpar a sujeira dos móveis \\ Sinto muito \\ Aprendi a ler".
}

(Sobral, 2011a).

\title{
Referências
}

SOBRAL, Cristiane. Espelhos, miradouros, dialéticas da percepção, contos. Brasília: Dulcina, 2011.

Não vou mais lavar os pratos. Poesia. 2. ed. Brasília: Dulcina, 2011a.

Só por hoje vou deixar o meu cabelo em paz. Poesia. Brasília: Teixeira, 2014.

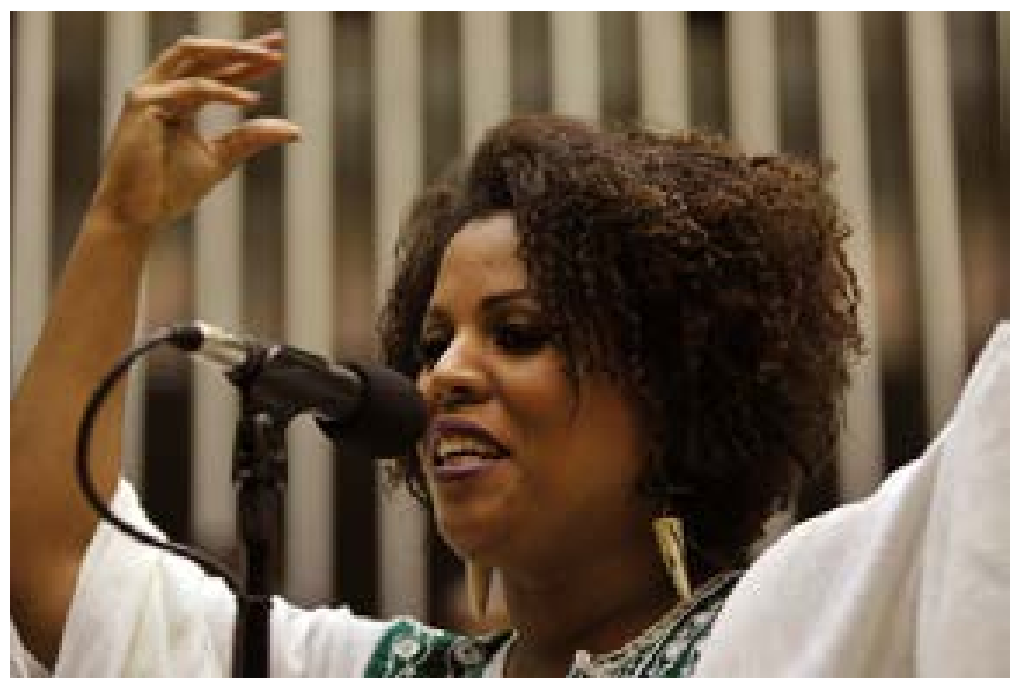

Cristiane Sobral em 24 de agosto de 2014.

Foto: Assessoria de Comunicação da Fundação Cultural Palmares

Recebido em: 30/01/2016

Aprovado em: 05/02/2016 